\title{
Interprofessional palliative care education for pediatric oncology clinicians: an evidence-based practice review
}

\author{
Sarah B. Green ${ }^{1,2^{*}}$ (D) and Adelais Markaki ${ }^{1}$
}

\begin{abstract}
Objective: Clinician education and expertise in palliative care varies widely across pediatric oncology programs. The purpose of this evidence-based practice review was to identify interprofessional palliative care education models applicable to pediatric oncology settings as well as methods for evaluating their impact on clinical practice.

Results: Based on a literature search in PubMed, CINAHL and Embase, which identified 13 articles meeting inclusion/exclusion criteria, the following three themes emerged: (1) establishment of effective modalities and teaching strategies, (2) development of an interprofessional palliative care curriculum, and (3) program evaluation to assess impact on providers' self-perceived comfort in delivering palliative care and patient/family perceptions of care received. Remarkably, health professionals reported receiving limited palliative care training, with little evidence of systematic evaluation of practice changes following training completion. Improving palliative care delivery was linked to the development and integration of an interprofessional palliative care curriculum. Suggested evaluation strategies included: (1) eliciting patient and family feedback, (2) standardizing care delivery measures, and (3) evaluating outcomes of care.
\end{abstract}

Keywords: Palliative care, Interprofessional education, Pediatric oncology, Evidence-based practice

\section{Introduction}

Children with cancer are a vulnerable population with complex needs. Despite advancements in treatments, cancer remains the fourth leading cause of death among children with up to $20 \%$ dying of their disease, and an even larger percentage experiencing physical and psychosocial suffering during and after treatment [1-4]. Early integration of palliative services into oncology care has been shown to reduce symptoms and suffering as well as to improve outcomes by providing meaningful person-and-family-centered care experiences $[3,5]$. It also reduces healthcare costs by decreasing hospitalization days and emergency department visits $[3,6,7]$. An integrated model for delivering palliative care (PC) throughout the continuum, starting at diagnosis, has

\footnotetext{
${ }^{*}$ Correspondence: sagreen@chla.usc.edu

${ }^{2}$ Children's Hospital Los Angeles, 4650 Sunset Blvd. \#54, Los Angeles, CA 90027-6062, USA

Full list of author information is available at the end of the article
}

been recommended [8]. This interprofessional approach requires highly skilled team members working together to meet the needs of the pediatric oncology patient and family [9].

Despite growing evidence about the benefits of PC in pediatric oncology, clinician education and expertise varies widely across programs. Differential, and often suboptimal access to services is a rising concern [3]. A staggering $89 \%$ of parents reported their child experienced significant suffering at end-of-life and that symptoms were successfully controlled less than $30 \%$ of the time [4]. In a 2013 survey of pediatric palliative care programs, $69 \%$ of institutions reported having a PC team [1]. Yet, the majority of pediatric oncologists (75\%) reported lacking formal training in end-of-life care [10]. This discrepancy suggests that PC expertise is concentrated in tertiary institutions with highly specialized teams, while oncology practices are lagging behind. To address this disparity, the National Consensus Project [9] issued guidelines calling for: (1) increasing the number 
of clinicians trained in interprofessional pediatric palliative care, and (2) expanding access to comprehensive PC teams throughout the continuum of care. Incorporating interprofessional education (IPE), training, and research for pediatric oncology providers is critical to improving quality of life for this population [2, 11, 12]. This evidence-based practice literature review aimed to identify potential knowledge gaps in regards to interprofessional palliative care education models, as well as methods for evaluating their impact on pediatric oncology practice.

\section{Main text \\ Methods}

The World Health Organization (WHO) Framework for Action on Interprofessional Education and Collaborative Practice definition for IPE was adopted [13]. For collaborative practice, the terms 'interdisciplinary' and 'multidisciplinary', often used interchangeably, were operationalized as follows: 'interdisciplinary' describes two or more academic disciplines working together to achieve a shared goal whereas, 'multidisciplinary' draws on the knowledge of different disciplines to work on a common problem with limited integrated interaction [14].

\section{Search strategy and data analysis}

A qualitative evidence synthesis was performed in PubMed, CINAHL, and Embase using the key search terms "education, interprofessional education, palliative care, multidisciplinary team, oncology, AND pediatrics." (see Fig. 1). Only full-text, peer reviewed research articles published in English within the past 5 years (January, 2012-October, 2017) were included. Articles on interprofessional education models pertaining to the adult, non-oncologic population were selected to reflect that core PC competencies cross the age spectrum of populations [9]. Exclusion criteria were based on absence of (1) clinician education focus, (2) an interprofessional or multidisciplinary approach, and (3) an educational intervention. A total of 13 articles met all criteria, including 12 articles at level VI evidence and 1 at a level I.

Thematic analysis of the literature sample is reported in Table 1 with themes derived from the WHO educator and curricular mechanisms, including training, program content, learning outcomes, and shared-decision-making processes.

\section{Results}

Three themes emerged from this integrative literature review: (1) establishing effective modalities and teaching strategies for content delivery, (2) developing an interprofessional palliative care curriculum, and (3) evaluating impact on providers' self-perceived comfort in delivering palliative care as well as patient and family perceptions of the care received (Table 1 ).

\section{Effective modalities and teaching strategies}

Effective modalities included face-to-face and webbased didactic content, in addition to clinical palliative care experiences. Head et al. [15] reported benefits and challenges for each modality, with a combination best meeting the needs and time constraints of students. Wittenberg-Lyles et al. [16] reported about an on-line palliative care curriculum, cautioning against an exclusive on-line curriculum which inhibits in-class face-toface interaction. Similarly, an in-person format extended classroom discussion and encouraged creative problem solving [17]. Shultz et al. [18] reported that medical students requested additional PC patient contact experiences for practical application.

"To teach practitioners who are already experienced in the field it is imperative that those involved in teaching have credible relevant expertise in children's palliative care" [17].

Only three studies were multi-modal, with web and face-to-face content [12, 18, 19]. All other programs consisted of a single modality and time-limited intervention, taking into account clinical practice demands and constraints [17, 20, 21]. Strategies for content delivery included multidisciplinary lectures from experts, simulation, role-play, group discussions, case-based learning, and on-line modules. Interactive teaching methods were integrated into the educational frameworks, highlighting the importance of communication in clinical practice $[17,18,21,22]$. Delivery of content in a variety of formats provided opportunity for didactic and experiential learning [18], such as conducting a quality-improvement (QI) project [12]. Collectively, these studies suggested that a multi-modal approach, incorporating a variety of teaching strategies, increased the availability of PC content to healthcare providers.

\section{Interprofessional curriculum}

National mandates requiring interprofessional PC practice were a driving force for curriculum development [17, 18]. Researchers aligned educational programs with the core competencies outlined in the consensus guidelines $[9,18,19,23]$.

Only one program, designed for practicing professionals, incorporated all core competencies utilizing an internationally validated pediatric curriculum; the Education in Palliative and End-of-Life Care for Pediatrics (EPEC-Pediatrics) [12]. Palliative care education that promoted communication and interprofessional engagement broadened awareness of team members' roles, and 


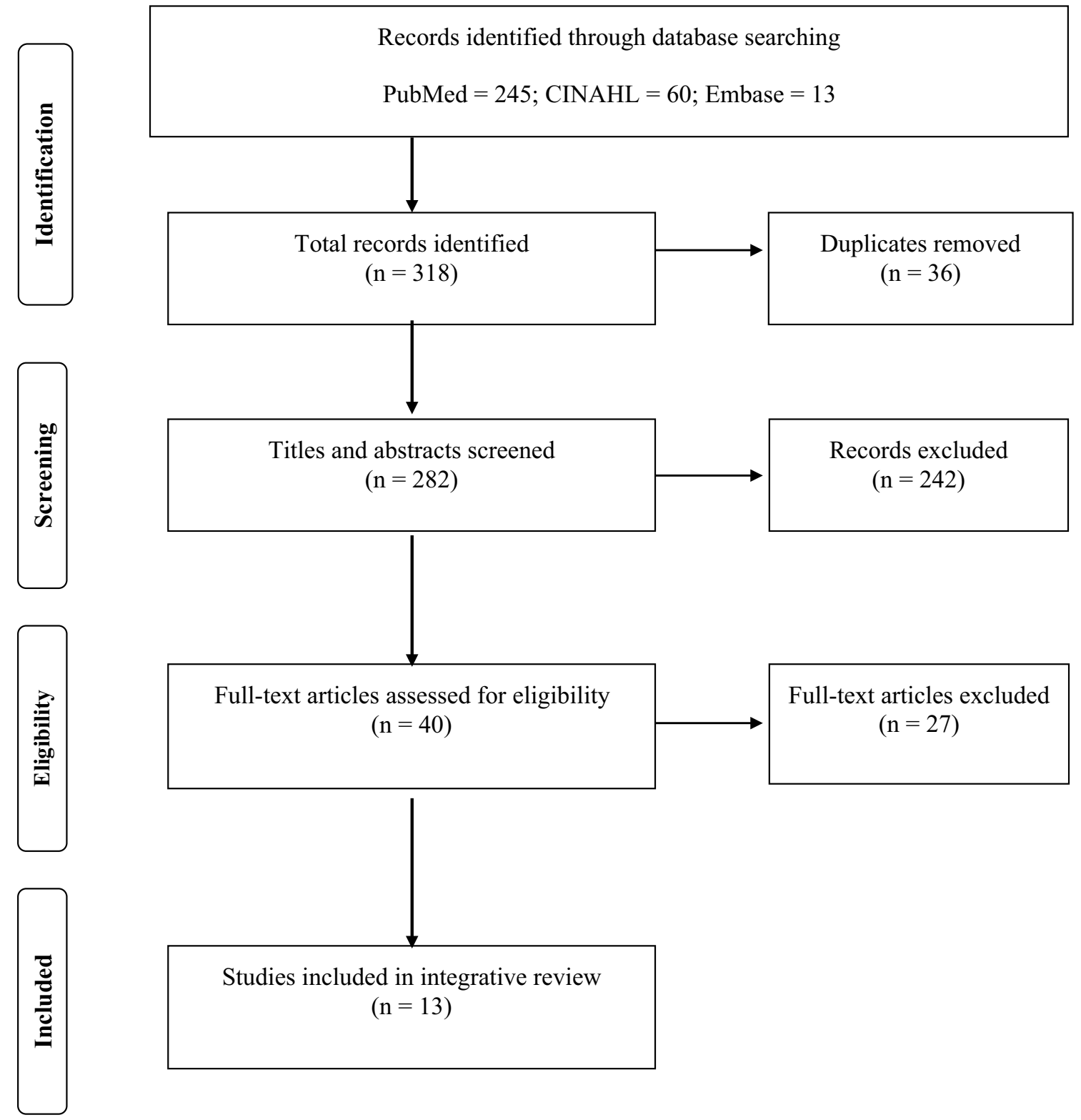

Fig. 1 Literature search flow chart

confidence in delivering palliative and end-of-life care $[17,20,23]$. The benefits of international IPE included sharing diverse professional experiences, and improving collaboration amongst disciplines [24]. Only one study focused exclusively on PC interprofessional communication training [20]. Use of the consensus guidelines provided a measure of standardization in palliative care education.

\section{Evaluating programs}

Program evaluations assessed content delivery and effectiveness in developing self-competency and comfort in the provision of palliative care. Evaluations determined the individual benefit to participants, in addition to the sustainability and adaptability of the curriculum, beyond pilot studies in single institutions $[18,21,25,26]$.

"All aspects of the program together make it an incredible educational experience. Each step has its own unique purpose and value" [21]. 


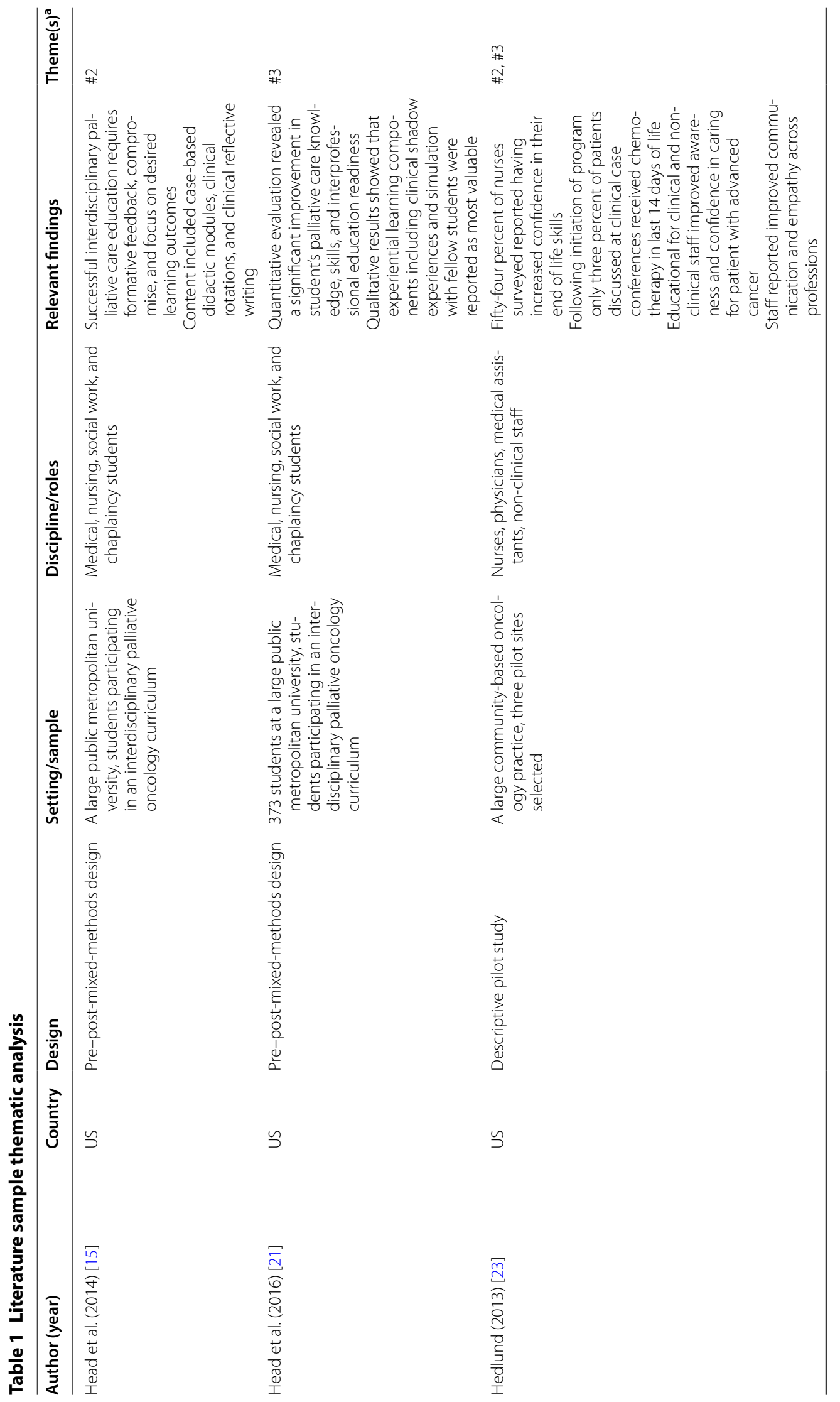




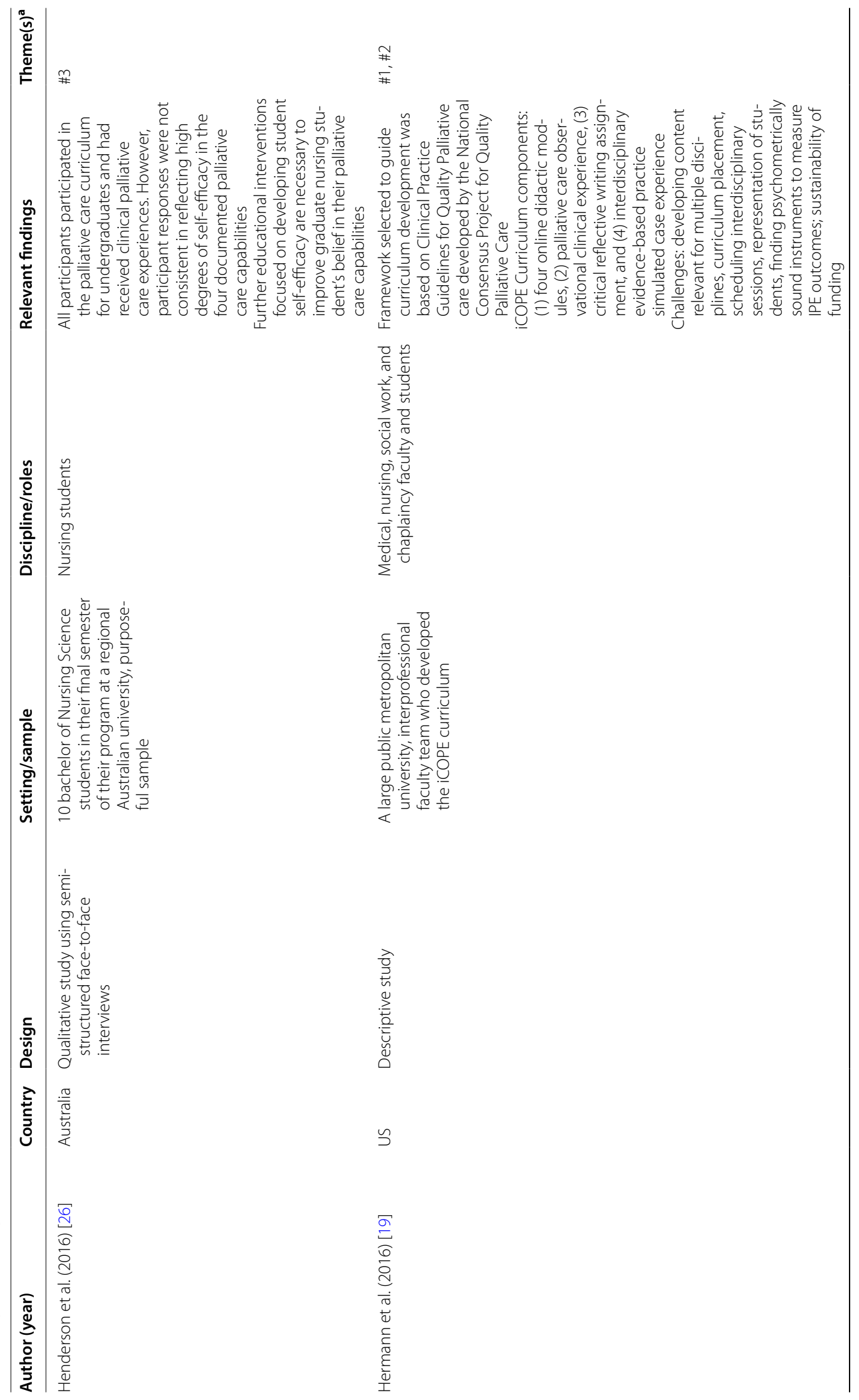




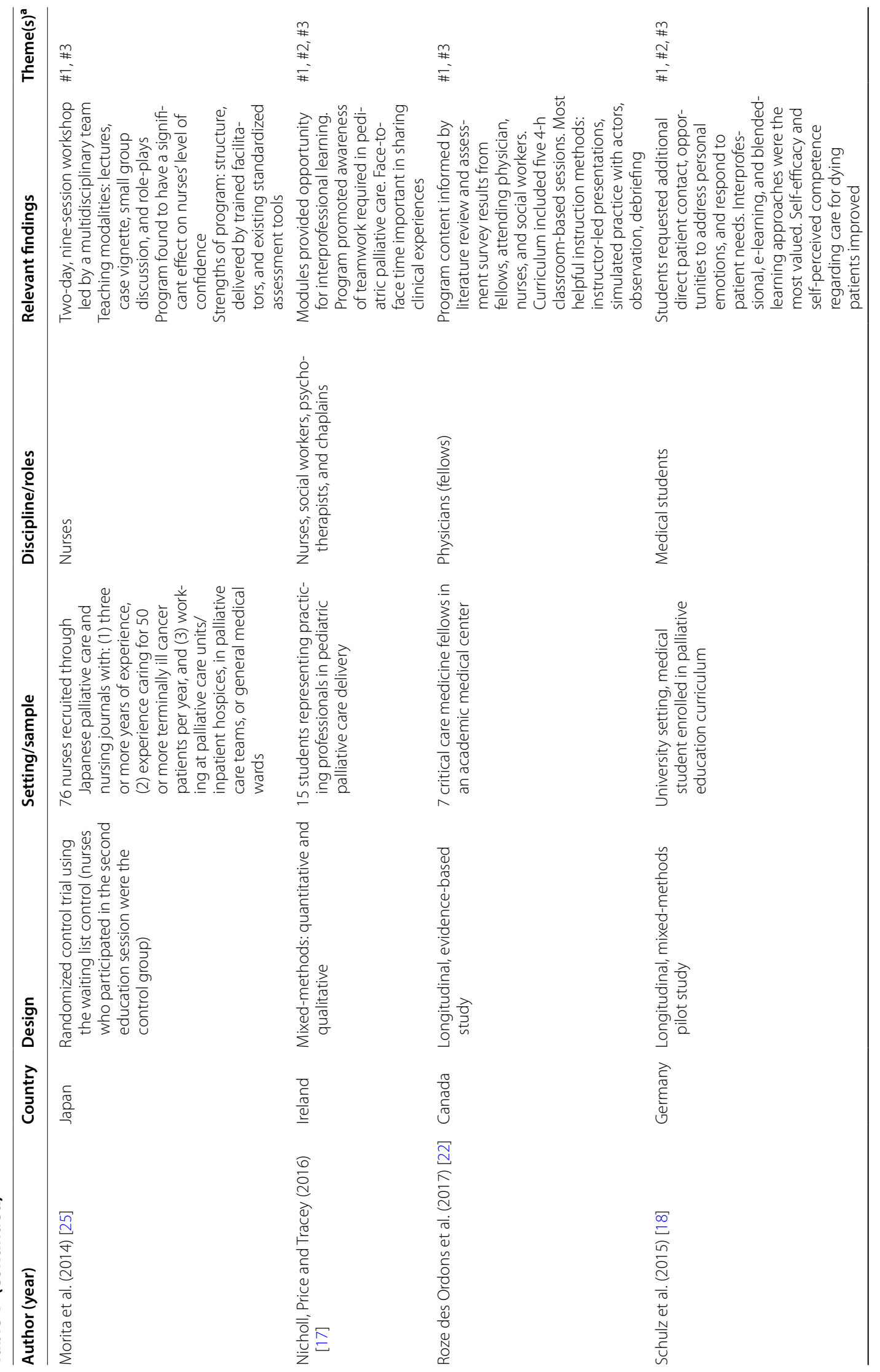




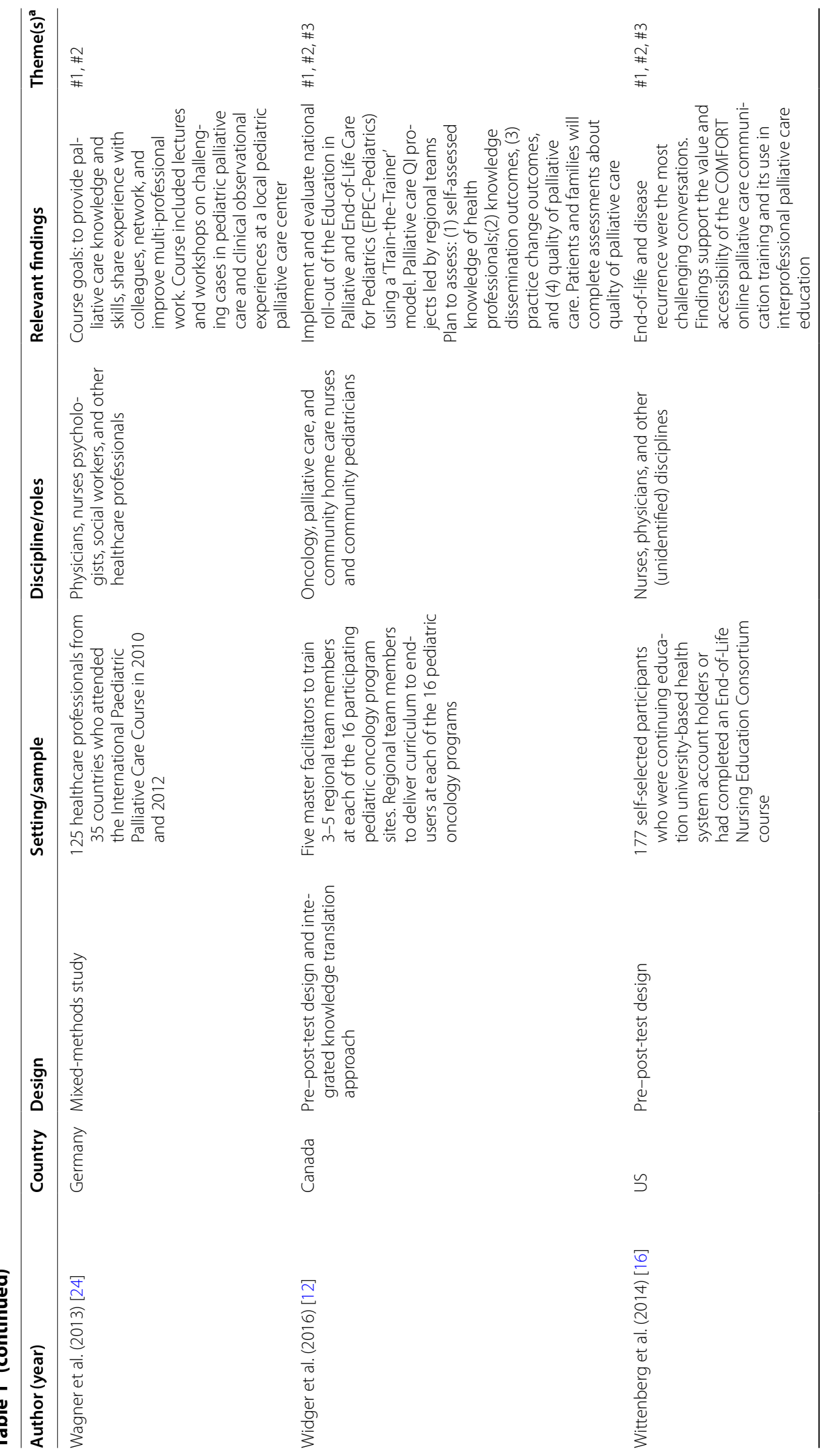




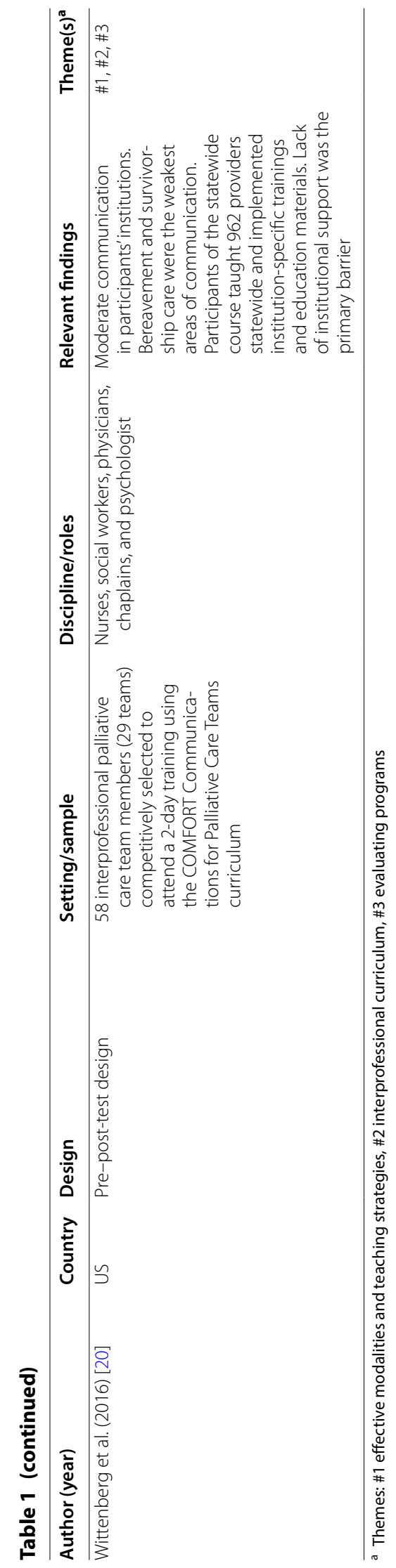


A validated confidence scale to assess nurses' confidence in caring for terminally ill cancer patients, before and after a two-day educational workshop, as well as other pre-post-test survey evaluation tools were used $[15,25]$. The End-of-Life Professional Caregiver Survey focused on the eight domains of the PC consensus guidelines. A second tool, the Self-Efficacy for Interprofessional Experiential Learning Scale, measured individuals' perceptions of engaging in a collaborative interprofessional team environment. A study by Wigder et al. [12] was the only one to evaluate provider, patients, and parent perceptions of PC experience, health-professionals' knowledge attainment, and dissemination of practice change outcomes at a national level.

\section{Discussion}

The benefits of implementing PC practice within the pediatric oncology population, and the importance of IPE are evident in this review. A notable gap was the limited evaluation of practice changes following completion of PC education. Self-report measures were important to evaluating content, and perceived comfort with PC engagement. However, there was no systematic evaluation of educational intervention impact on care delivery. Although clinicians' self-reported measures are discussed, there is little focus on evaluating how skills and knowledge directly impact providing holistic care, engaging in critical conversations, and effectively managing symptoms. In accordance with the WHO Framework for Action [13], interprofessional palliative care can be evaluated by: (1) patient and family feedback regarding providers' palliative care competency, (2) standardized measures that analyze the effect on care delivery, and (3) outcomes of care.

\section{Eliciting feedback}

Validating patients' and families' perspectives in order to best understand the patient experience has been strongly recommended [27]. Family meetings and daily rounding are two informal methods, utilizing routine clinical care for eliciting patient and family perspectives. Individual patient and parent evaluations, focus groups, and technology-based survey evaluations are formal methods for collecting patient and family feedback [28].

\section{Standardizing measures}

The goal of a PC educational curriculum is to directly impact the quality of patient care [12]. To evaluate this impact, valid and reliable measurements must be utilized [29]. The majority of tools focused on clinician self-reported measures, while there was a lack of patient and caregiver tools evaluating perceptions of PC delivery, with the exception of one study. Psychometrically tested instruments are highly desirable. Lown and McIntosh [27] recommended establishing a shared web-based repository for compassionate collaborative care (CCC) tools. Developing a similar repository for PC instruments and measurements would be an effective way to disseminate and make accessible to pediatric oncology clinicians. In return, this would inform evidence-based clinical practice and spearhead research and a growing body of literature. Measurement tools specific to the pediatric palliative care population could be housed on the National Hospice and Palliative Care Organization website.

\section{Evaluating outcomes of care}

Evaluation of PC education should extend beyond the direct impact on individual patients to clinicians as well. Potential benefits include patient and family member reported quality-of-life, clinical care outcomes and satisfaction [27]. Potential fiscal impact measures include decreased emergency department visits and re-admissions for symptom management $[1,6]$. Tracking valuebased outcomes with the support of the National Hospice and Palliative Care Organization could provide a robust evaluation of impact on clinical practice. It has been argued that to fully operationalize and sustain patient and family-centered care in palliative practice settings, compassion and collaboration must be enacted and harmonized [30]. Towards that direction, quality indicators for CCC can guide the planning and implementation of changes at a pediatric hospital, such as patient care conferences, institutional palliative care rounds, establishment of a Compassionate Care Network, and bereavement debriefing [30]. All of these CCC indicators are potentially tied to interprofessional palliative care education within pediatric oncology settings, but further research would be needed to demonstrate associations and effect.

\section{Implications}

Given that PC should begin as early as a diagnosis of a life-limiting condition is set, the majority of pediatric oncology patients and families could benefit. To this direction, the Palliative Care and Hospice Education and Training Act of 2017 (H.R. 1676) [31] requests funding provisions to promote interprofessional education and research. Financial support for Palliative Care and Hospice Education Centers, provided through H.R. 1676, would have a direct impact in: (1) increasing the number of interprofessional palliative care faculty in academic and clinical settings; (2) promoting education and research in PC and hospice, and (3) standardizing PC education for patients, families and healthcare professionals. 


\section{Conclusions}

Although pediatric oncology clinicians care for patients with life-threatening illnesses, there is great variation in their formal palliative care training. Essential components for successful pediatric palliative care educational programs include: (1) establishing effective modalities and teaching strategies for content delivery, (2) developing an interprofessional palliative care curriculum, and (3) evaluating programs. Despite limited evidence of the effects on pediatric oncology practice, suggested evaluation methods are: (1) eliciting patient and family feedback, (2) standardizing care delivery measures, and (3) evaluating outcomes of care.

\section{Limitations}

To our knowledge, this was the first study addressing palliative care education for pediatric oncology clinicians through an interprofessional lens. Given the on-going debate in Congress, our findings are both timely and relevant to the national health policy agenda. Limitations stem from the lack of high-level evidence available on this topic (no systematic reviews or meta-analysis studies met inclusion criteria). Studies utilized clinician selfreport measures and there was no systematic evaluation of educational intervention impact on care delivery. Only one study was multi-modal, with all others consisting of a single modality and time-limited interventions. One program incorporated all core competencies, with only one study utilizing an internationally validated pediatric curriculum. Further longitudinal and multi-site studies are needed to standardize clinician education and develop psychometrically tested tools to establish best practice recommendations.

\section{Authors' contributions}

SG conceived the study as part of DNP coursework, conducted the search, extracted and screened articles, analyzed and synthesized the data, drafted the manuscript. AM provided faculty advisor expertise, synthesized and interpreted the data, revised the manuscript. Both authors read and approved the final manuscript.

\section{Author details}

1 School of Nursing, University of Alabama at Birmingham, 1720 2nd Ave. South, Birmingham, AL 35294-1210, USA. ${ }^{2}$ Children's Hospital Los Angeles, 4650 Sunset Blvd. \#54, Los Angeles, CA 90027-6062, USA.

\section{Acknowledgements}

SG acknowledges the support from Jennifer Baird, Ph.D., MPH, MSW, RN, CPN who reviewed and provided feedback on an earlier class assignment version.

\section{Competing interests}

The authors declare that they have no competing interests.

\section{Availability of data and materials}

The datasets analyzed during the current study are available from the corresponding author on reasonable request.

\section{Consent for publication}

Not applicable.
Ethics approval and consent to participate

Not applicable (non-human subjects study).

Funding

Not applicable.

\section{Publisher's Note}

Springer Nature remains neutral with regard to jurisdictional claims in published maps and institutional affiliations.

Received: 5 September 2018 Accepted: 1 November 2018

Published online: 07 November 2018

References

1. Friebert S, Williams C. NHPCO's facts and figures: Pediatric palliative \& hospice care in America. 2015. https://www.nhpco.org/sites/default/files/ public/quality/Pediatric_Facts-Figures.pdf. Accessed 8 July 2018.

2. Montgomery K, Sawin KJ, Hendricks-Ferguson VL. Experiences of pediatric oncology patients and their parents at end of life: a systemic review. JOPON. 2016;33(2):85-104. https://doi.org/10.1177/1043454215589715.

3. Weaver MS, Heinze KE, Bell CJ, Wiener L, Garee AM, Kelly KP, et al. Establishing psychosocial palliative care standard for children and adolescents with cancer and their families: an integrative review. Palliat Med. 2016;30(3):212-23. https://doi.org/10.1177/0269216315583446.

4. Wolfe J, Hammel J, Edwards K, Duncan J, Comeau M, Bryer J, et al. Easing of suffering in children with cancer at the end of life: is care changing? JCO. 2008;26(10):1717-23.

5. Bagcivan G, DionneOdom JN, Frost J, Plunkett M, Stephens LA, Bishop, et al. What happens during early outpatient palliative care consultations for persons with newly diagnosed advanced cancer? A qualitative analysis of provider documentation. Palliat Med. 2018;32(1):59-68. https://doi. org/10.1177/0269216317733381.

6. Ananth P, Melvin P, Berry JG, Wolfe J. Trends in hospital utilization and costs among pediatric palliative care recipients. Palliat Med. 2017;20(9):946-53. https://doi.org/10.1089/jpm.2016.0496.

7. Gans D, Hadler MW, Chen X, Wu SH, Dimand R, Abramson JM, et al. Cost analysis and policy implications for a pediatric palliative care program. JPSM. 2016;52(3):329-35. https://doi.org/10.1016/j.jpainsymma n.2016.02.020.

8. American Academy of Pediatrics, Committee on Bioethics and Committee on Hospital Care. Palliative care for children. Pediatrics. 2000; 106(2): 351-57. http://pediatrics.aappublications.org/content/pediatrics /106/2/351.full.pdf. Accessed 8 July 2018.

9. National Consensus Project. Clinical practice guidelines for quality palliative care. 2013. http://www.nationalcoalitionhpc.org/ncp-guidelines -2013. Accessed 8 July 2018.

10. Brian JW. The need for increased access to pediatric hospice and palliative care. Dimens Crit Care Nurs. 2011;30(5):231-5. https://doi.org/10.1097/ DCC.0b013e3182276ded

11. Ranallo L. Improving the quality of end-of-life care in pediatric oncology patients through the early implementation of palliative care. JOPON. 2017;34(6):374-80. https://doi.org/10.1177/1043454217713451.

12. Widger K, Friedrichsdorf S, Wolfe J, Liben S, Pole J, Bouffet E, et al. Protocol: evaluating the impact of a nation-wide train-the-trainer educational initiative to enhance the quality of palliative care for children with cancer. BMC Palliat Care. 2016;15:12. https://doi.org/10.1186/s12904-016-0085-8.

13. World Health Organization (WHO). Department of Human Resources for Health. Framework for action on interprofessional education and collaborative practice. 2010. Ref\#:WHO/HRH/HPN/10.3 http://www.who.int/hrh/ resources/framework_action/en/. Accessed 26 June 2018.

14. Choi BC, Pak AW. Multidisciplinarity, inderdisciplinarity and transdisciplinarity in health research, services, education and policy: 1. Definitions, objectives, and evidence of effectiveness. JIM. 2006; 29(6): 351-64. http:// www.cimonline.ca/index.php/cim. Accessed 8 July 2018.

15. Head BA, Schapmire T, Hermann C, Earnshaw L, Faul A, Jones C, et al. The interdisciplinary curriculum for oncology palliative care education (iCOPE): meeting the challenges of interprofessional education. Palliat Med. 2014;17(10):1107-14. https://doi.org/10.1089/jpm.2014.0070. 
16. Wittenberg-Lyles E, Goldsmith J, Ferrell B, Burchett M. Assessment of an interprofessional online curriculum for palliative care communication training. Palliat Med. 2014;17(4):400-6. https://doi.org/10.1089/jpm.0270.

17. Nicholl H, Price J, Tracey C. An evaluation of an interprofessional master's level programme in children's palliative care: the student's evaluation. Nurse Educ Pract. 2016;17:60-5. https://doi.org/10.1016/j. nepr.2014.03.007.

18. Schulz C, Wenzel-Meyburg U, Karger A, Scherg A, Schmitten J, Trapp T, et al. Implementation of palliative care as a mandatory cross-disciplinary subject (QB13) at the Medical Facility of the Heinrich-Heine-University Dusseldorf. Germany. GMS Z Med Ausbild. 2015;32(1):1-11. https://doi. org/10.3205/zma000948.

19. Hermann CP, Head BA, Black K, Singleton K. Preparing nursing students for interprofessional practice: the interdisciplinary curriculum for oncology palliative care education. J Prof Nurs. 2016;32(1):62-71. https://doi. org/10.10106/j.profnurs.2015.06.00.

20. Wittenberg E, Ferrel B, Goldsmith J, Ragan SL, Paice J. Assessment of a statewide palliative care team training course: COMFORT communication for palliative care teams. Palliat Med. 2016;19(7):746-52. https://doi. org/10.1089/jpm.2015.0552

21. Head BA, Schapmire T, Hermann C, Earnshaw L, Faul A, Hermann C, et al. Evaluation of an interdisciplinary curriculum teaching team-based palliative care integration in oncology. J Cancer Educ. 2016;31 (2):358-65. https ://doi.org/10.1007/s13187-015-0799-y.

22. RozedesOrdons AL, Doig CJ, Couillard P, Lord J. From communication skills to skillful communication: a longitudinal integrated curriculum for critical care medicine fellows. Acad Med. 2017;92(4):501-5.

23. Hedlund S. Northwest cancer specialists (NCS) care: coordinated, advocacy, resources, education, and support: a palliative care program in an outpatient oncology practice. J Death Dying. 2013;67(1-2):109-13. https ://doi.org/10.2190/OM.67.1-2.I
24. Wagner J, Zernikow B, Drake R, Papadatou D, Hubner-Mohler B, Bluebond-Langner M. International multiprofessional course in pediatric palliative care: benefits and challenges. Palliat Med. 2013;16(1):96-9. https ://doi.org/10.1089/jpm.2012.0255.

25. Morita T, Tamura K, Kusajima E, Sakai S, Kawa M, Imura C, et al. Nurse education program on meaninglessness in terminally ill cancer patients: a randomized controlled study of a novel two-day workshop. Palliat Med. 2014;17(12):1289-305. https://doi.org/10.1089/jpm.2013.0559.

26. Henderson A, Rowe J, Watson K, Hitchen-Holmes D. Graduating nurses' self-efficacy in palliative care practice: an exploratory study. Nurs Educ Today. 2016;39:141-6. https://doi.org/10.1016/j/nedt.2016.01.00.

27. Lown B, McIntosh S. (Eds.). Advancing compassionate, person-and family centered care through interprofessional education for collaborative practice. Report presented at the Compassionate Collaborative Care Conference, Atlanta, GA. 2014. http://www.theschwartzcenter.org/media Triple-C-Conference-Recommendations-Report_FINAL1.pdf. Accessed 8 July 2018.

28. Virdun C, Brown N, Phillips J, Luckett T, Agar M, Green A, et al. Elements of optimal pediatric palliative care for children and young people: an integrative review using a systematic approach. Collegian. 2015;22:421-31. https://doi.org/10.1016/j.colegan.2014.07.001.

29. Aslakson RA, Dy SM, Wilson RF, Waldfogel J, Zhang A, Isenberg SR, et al. Patient- and caregiver-reported assessment tools for palliative care: summary of the 2017 agency for healthcare research and quality technical brief. J Pain Symptom Manage. 2017;54(6):961-72. https://doi. org/10.1016/j.jpainsymman.2017.04.022.

30. Pfaff K, Markaki A. Compassionate collaborative care: an integrative review of quality indicators in end-of-life care. BMC Palliat Care. 2017;16:65. https://doi.org/10.1186/s12904-017-0246-4.

31. Palliative Care and Hospice Education and Training Act of 2017, H.R. 1676, 115th Cong. 2017.
Ready to submit your research? Choose BMC and benefit from:

- fast, convenient online submission

- thorough peer review by experienced researchers in your field

- rapid publication on acceptance

- support for research data, including large and complex data types

- gold Open Access which fosters wider collaboration and increased citations

- maximum visibility for your research: over 100M website views per year

At BMC, research is always in progress.

Learn more biomedcentral.com/submissions 